Article

\title{
Loss of Mitochondrial Genetic Diversity in Overexploited Mediterranean Swordfish (Xiphias gladius, 1759) Population
}

\author{
Tommaso Righi, Andrea Splendiani, Tatiana Fioravanti, Elia Casoni, Giorgia Gioacchini, \\ Oliana Carnevali and Vincenzo Caputo Barucchi *
}

Dipartimento di Scienze della Vita e dell'Ambiente, Università Politecnica delle Marche, Via Brecce Bianche, 60131 Ancona, Italy; t.righi@pm.univpm.it (T.R.); andreasplendiani@hotmail.com (A.S.);

t.fioravanti@pm.univpm.it (T.F.); eliacasoni@libero.it (E.C.); giorgia.gioacchini@staff.univpm.it (G.G.);

o.carnevali@staff.univpm.it (O.C.)

* Correspondence: v.caputo@staff.univpm.it

Received: 4 March 2020; Accepted: 24 April 2020; Published: 26 April 2020

\begin{abstract}
Intense and prolonged mortality caused by over-exploitation could drive the decay of genetic diversity which may lead to decrease species' resilience to environmental changes, thus increasing their extinction risk. Swordfish is a high commercial value species, especially in the Mediterranean Sea, where it is affected by high catch levels. Mediterranean swordfish consist of a population genetically and biologically distinct from Atlantic ones and therefore managed as a separate stock. The last Mediterranean swordfish stock assessment reported that in the last forty years Mediterranean swordfish has been overfished and, to date, it is still subject to overfishing. A comparison between an available mitochondrial sequence dataset and a homologous current sample was carried out to investigate temporal genetic variation in the Mediterranean swordfish population over near twenty years. Our study provides the first direct measure of reduced genetic diversity for Mediterranean swordfish during a short period, as measured both in the direct loss of mitochondrial haplotypes and reduction in haplotype diversity. A reduction of the relative females' effective population size in the recent sample has been also detected. The possible relationship between fishery activities and the loss of genetic diversity in the Mediterranean swordfish population is discussed.
\end{abstract}

Keywords: Mediterranean Sea; mtDNA; control region; swordfish

\section{Introduction}

The swordfish (Xiphias gladius) is a large pelagic and migratory fish found in the open waters of all oceans, including the Mediterranean Sea [1]. Swordfish migration is complex and multi-directional [1]. Seasonally adults swordfish migrate for reproductive reasons to spawning grounds, while a diel pattern in vertical movement occurring for feeding, reaching deep water (300-600 m) during daylight and staying closer to the sea-surface during the night $[2,3]$. Swordfish growth is relatively rapid and sexually dimorphic. Females generally reach a larger maximum size than males and large individuals are usually female [2,4]. Mediterranean swordfish consist of a population genetically and biologically distinct from the Atlantic one. The growth parameters are different, and the sexual maturity is reached at younger ages than in the Atlantic [4]. In the Mediterranean, the estimated size at which $50 \%\left(\mathrm{~L}_{50}\right)$ of the female population is mature occurs from $131.5 \mathrm{~cm}$ [5] and $140 \mathrm{~cm}$ [6], corresponding to 3-4-year-old fish [2]. Males reach sexual maturity at smaller sizes and mature specimens have been found at about $90 \mathrm{~cm}$ (Lower jaw fork length, LJFL) [7]. Genetic differentiation [8], as well as several differences in biological parameters [2], have been used to identify and manage the Atlantic and Mediterranean 
swordfish as separated stocks [7]. A popular genetic marker used to examine swordfish populations is the mitochondrial control region (D-loop). As reported for other large pelagic species (Thunnus alalunga [9]; Thunnus thynnus [10] Seriola dumerili [11]) the mitochondrial control region of swordfish can be divided into two divergent clades. Specifically for swordfish, a ubiquitous Clade I widespread in all stocks, and Clade II which decreases in abundance with distance from the Mediterranean Sea $[10,12,13]$ and is absent from the Pacific Ocean [14-16]. These phylogeographic associations support the inferred pattern of unidirectional historical gene flow from the Indo-Pacific into the Atlantic and the Atlantic origin of Clade II [10]. A subdivision in two monophyletic subclades to the Atlantic and Mediterranean Clade II lineage confirmed genetic isolation between the two stocks [10,13]. Furthermore, within the Mediterranean Sea Swordfish population sub-structuring was suggested based on a clinal decrease in mitochondrial DNA control region intra-clade genetic variability from Western and the Eastern basins [17]. The Mediterranean population showed the lowest levels of genetic variation compared to any other population worldwide $[10,12,13,18,19]$. According to Bremer et al. [10], the reduced level of variation in Mediterranean swordfish mtDNA is congruent with multiple faunal extinctions and subsequent re-colonization events occurred during the Pleistocene. However, according to Kotoulas et al. [20], the low genetic variability observed using nuclear markers could be related to the small effective population size of Mediterranean swordfish, probably caused by fishing pressure [19]. Moreover, according to Arocha [4], prolonged exploitation of swordfish in the Mediterranean area may have reduced the numbers of older specimens and consequently explain the lower mean size of the catches and lower size of maturation observed for the Mediterranean population.

Swordfish is a high commercial value species, especially in the Mediterranean Sea, where despite this basin represents less than $10 \%$ of the swordfish global range, catch levels are relatively high and similar to those of larger areas such as the North Atlantic [21]. Some characteristics as the presence of a larger spawning area in relation to the area of distribution of the stock, lower abundance of predators and higher recruitment were suggested as the determining factors explaining the higher abundance of swordfish in the Mediterranean Sea. However, in the last forty years, the swordfish stock of the Mediterranean Sea has been overfished and, to date, is still subject to overfishing [7]. The Spawning Stock Biomass (SSB) estimated represents less than $15 \%$ of the maximum sustainable yield (BMSY) and the fish mortality caused by harvesting $(\mathrm{F})$ is almost twice the maximum sustainable yield. The $50-70 \%$ of the total yearly catches is represented by fish of small size often less than 3 years old, with a high level of immature swordfish reported [7]. The loss of genetic variation caused by population reduction is an important concern in fisheries management. Intense and prolonged mortality caused by overexploitation could drive the decay of genetic diversity across a wide range of marine fishes [22]. Genetic diversity has been defined as the variety of alleles and genotypes present in a population and that is reflected in morphological, physiological and behavioral differences between individuals and populations [23]. The reduction of genetic diversity may lead to decreased species resilience to environmental changes, thus increasing their extinction risk [23,24]. Small and isolated populations are more vulnerable to genetic degradation [23]. Moreover, in marine fishes, effective population size $(\mathrm{Ne})$ can be several orders of magnitude smaller than census size $(\mathrm{N})$ [25-27] and species may suffer a loss of genetic diversity under fishing pressure despite large census size.

The most powerful way to detect loss of genetic variation in exploited populations is the examination of genetic samples collected over time [28]. In this study, a dataset of available mitochondrial sequences of Mediterranean swordfish sampled in the 1990s and early 2000s has been compared with homologous mtDNA data obtained from current samples (2016-2018). This comparison was carried out to investigate if a temporal genetic variation occurred in the Mediterranean swordfish, where this species is considered threatened [21] and overexploited. 


\section{Materials and Methods}

\subsection{Sampling and DNA Extraction}

A total of 287 swordfish were collected from six areas within the eastern, central and western Mediterranean regions, trying to obtain a representative coverage of the basin (For details see Table 1 and Figure 1).

Table 1. Sampling details for swordfish analyzed in this study.

\begin{tabular}{cccc}
\hline $\begin{array}{c}\text { Sampling Area (FAO Fishing } \\
\text { Area/Geographical Subarea) }\end{array}$ & Sampling Date & n & $\begin{array}{c}\text { Mean LJFL (cm) } \\
\text { (s.d.) }\end{array}$ \\
\hline Balearic Sea (GSA 5, 6) & July 2016-August 2016-September 2016 & September 2019 & $122.1(22,2)$ \\
Southern Sicily (GSA 15, 16) & July 2016 & & $133.7(32.0)$ \\
& June 2017-July 2017 & 59 & \\
Aegean Sea (GSA 22) & June 2018 & 17 & $124.2(21.0)$ \\
South Adriatic Sea (GSA 18) & August 2016 & 62 & $113.5(16.6)$ \\
Tyrrhenian Sea (GSA 10) & September 2016 & 16 & $120.8(23.8)$ \\
Sardinian Sea (GSA 11.2) & May 2017 & 49 & $125.0(32.6)$ \\
Total & June 2017-October 2017 & 49 & \\
\hline
\end{tabular}

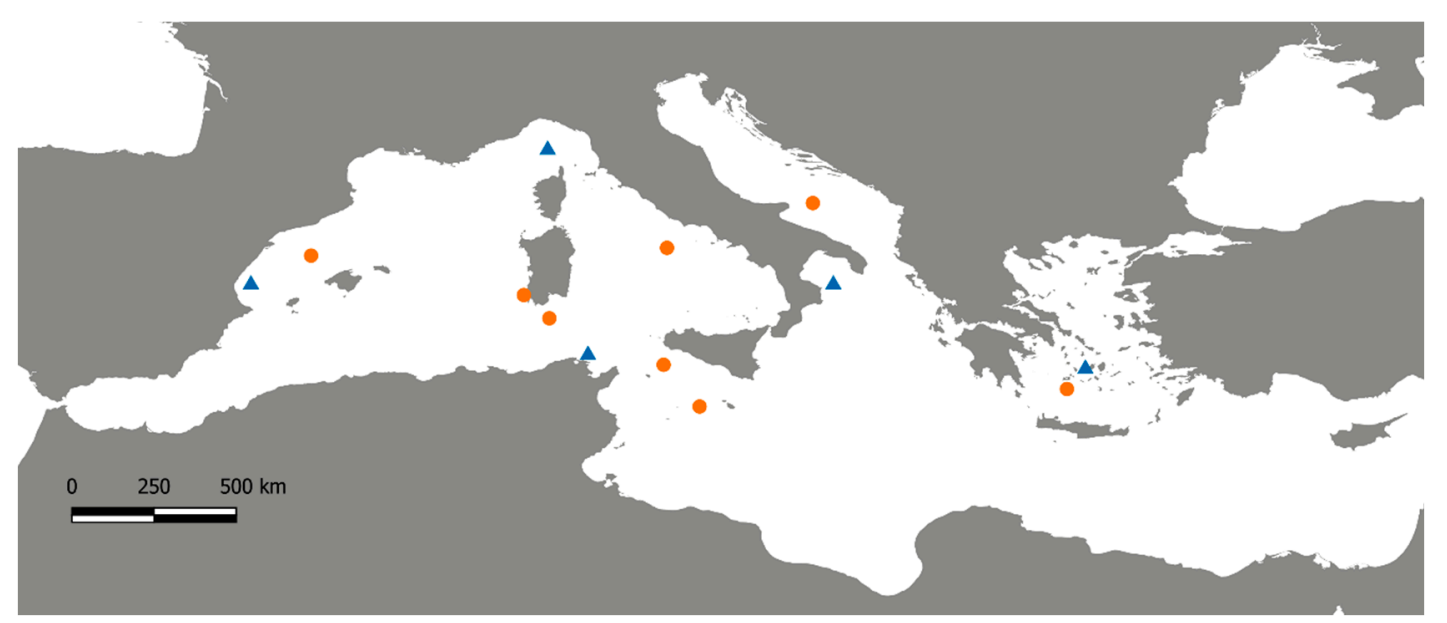

Figure 1. Map of the Mediterranean Sea with the Swordfish sampling sites. Blue triangles represent historical sampling localities from Viñas et al. [17] and orange dots represent sampling locations of current Swordfish samples.

Samples were achieved at the fishing landing of commercial catch by longline or trap bycatch (only in case of Sardinian samples) from May to October in three years 2016-2018. For each individual, a piece of the caudal fin was collected and was stored in ethanol absolute and kept at $-20^{\circ} \mathrm{C}$ until DNA extraction. Total genomic DNA was extracted using specific cartridge 401 in the MagCore ${ }^{\circledR}$ automated Nucleic Acid extractor (RBC Bioscience, New Taipei City, Taiwan) following the specific protocol. Historical mitochondrial data were obtained from a re-analysis of the dataset available from Viñas [17] (Table S2). That work included specimens sampled in several Mediterranean areas (Figure 1) from 1992 to 1995 and the early 2000s (see [11] for sample details), allowing us to evaluate the mitochondrial genetic variability between two complementary sample groups of Mediterranean swordfish over a 20-year period. 


\subsection{Mitochondrial DNA Amplification and Analysis}

PCR-RFLP (Restrictin Fragment Length Polymorphism) analysis was performed to identify the two mitochondrial lineages. The restriction enzymes were selected by virtual restriction analysis (see Supplementary material S3 for virtual analysis details). A 360 bps long portion of the hypervariable L-domain of the mitochondrial control region was amplified using primers L15998 (5'-TAC CCC AAA CTC CCA AAG CTA-3') [12] and SWO 5' CCC TGT GAA ATA TGC TGG TTG 3' (designed in this study). The amplification was carried out in $25 \mu \mathrm{L}$ reaction volume containing: $1 \times$ MyTaq reaction buffer (BioLine $\mathrm{GmbH}$, Luckenwalde, Germany), 10 pmol of each primer, $0.5 \mathrm{U}$ of BIOTAQ DNA-Polymerase (BioLine GmbH, Luckenwalde, Germany) and approximately $80 \mathrm{ng}$ of the isolated DNA. For thermal cycler Viñas et al. [9] has been followed. Amplicons were double-digested with selected PacI and VspI restriction enzymes (Thermo Fisher Scientific, Waltham, Massachusetts, MA, USA). The digestion mix reaction was carried out in a total volume of $20 \mu \mathrm{L}$ with $4 \mu \mathrm{L}$ of amplified DNA, $2 \mu \mathrm{L}$ of Buffer G 10X (Thermo Fisher Scientific, Waltham, Massachusetts, MA, USA), and $0.3 \mu \mathrm{L}$ $[10 \mathrm{U} / \mu \mathrm{L}]$ of each enzyme. The digestion took place at $37^{\circ} \mathrm{C}$ overnight. Restriction profiles were visualized in $2 \%$ agarose gel. Subsequently, to screen mitochondrial genetic variability a PCR-SSCP (Single Strand Conformation Polimorphism) analysis was performed. $5 \mu \mathrm{L}$ amplicon was added to $4 \mu \mathrm{L}$ loading buffer ( $98 \%$ formamide, $10 \mathrm{mM}$, EDTA ( $0.5 \mathrm{M}, \mathrm{pH}$ ) $), 0.05 \%$ bromophenol blue, $0.05 \%$ xylene cyanol), heated to $95{ }^{\circ} \mathrm{C}$ for $5 \mathrm{~min}$ and immediately chilled on ice. Vertical electrophoresis run was performed in a nondenaturing polyacrylamide gel ( $8 \%$ acrylamide/polyacrylamide [49:1], $10 \%$ glycerol) at $5 \mathrm{~W}$ for $12 \mathrm{~h}$ at room temperature, with $1 \times \mathrm{TBE}$ as the running buffer. To identify different haplotypes Sanger sequencing of $D$-loop was performed on a subsample for each SSCP pattern on an ABI 3730XL DNA (Applied Biosystems, Foster City, CA, USA). To validate the sensitivity of SSCP technique in the identification of different haplotypes, all individuals belonging to the Clade II lineage, which showed a fewer number of SSCP morphs, were sequenced. Sequences were aligned using ClustalW [29] and checked by eye in BioEdit [30]. Analysis of sequence variability was analyzed pooling all samples together and, following Viñas [17] grouping samples in Western (Balearic, Sardinian, Tyrrhenian) and Eastern (Sicilian, Adriatic and Aegean), according to the basin of origin. However, no genetic differentiation was detected by AMOVA (Analysis of Molecular VAriance) between the western and eastern group therefore we reported the only comparison among whole historical and contemporary datasets.

The number of haplotypes $(N)$, and polymorphic site, haplotypic $(h)$ and nucleotide diversities $(\pi)$ were computed in Arlequin v. 3.5 [31]. The analysis was performed for both dataset pooling Clades I and II together, and for each clade separately. To account for the sampling variance of haplotypic richness, rarefaction curves [32] were generated for both samples. Rarefaction curves were generated using iNEXT $[33,34]$. Median-joining (MJ) networks for the entire dataset were built using the software Network v 4.510 [35] with the default settings.

The extent of genetic differentiation between historical and contemporary datasets was investigated with an analysis of molecular variance, AMOVA [36], and the exact tests of population differentiation implemented in Arlequin [31]. The AMOVA significance levels were determined by 10,000 permutations while the exact test was conducted by using 10,000 Markov chain steps and 1000 dememorization steps.Finally, temporal changes in the relative effective number of females $\left(N_{e f}\right)$ was estimated comparing $\theta$ for each dataset. The $\theta$ is expected to be equal to $2 N_{\text {ef }} \mu$ for neutral mutations in mtDNA, where $\mu$ is the mutation rate per generation and $N_{e f}$ is the effective population size of females. Considering $\mu$ to be constant between two temporal samples, we can treat differences in $\theta$ among samples as differences in relative female effective population sizes. Population size parameter $(\theta)$ was inferred for each dataset using the maximum likelihood (ML) inference in LAMARC 2.1 [37] using Watterson's estimator as starting points, default model of evolution was used. A Markov Chain Monte Carlo was run for ten short chains and three long chains with 1000 and 10,000 recorded genealogies, respectively, after discarding the first 10,000 genealogies. One of every 20 reconstructed genealogies was sampled for both short and long chains. 


\section{Results}

The SSCP analysis of 360 bps portion of mtDNA D-loop from 287 contemporary Mediterranean swordfish revealed 36 different morphs. For each morph, a subsample has been sequenced for a total of 172 swordfish, corresponding to $60 \%$ of the total sample. The sequencing of all individuals belonging to the Clade II corroborated the SSCP profile interpretation. The sequence length ranged from 290 to 297 bps due to the presence of 1-3 tandemly repeated copies of the motif TACA near the $5^{\prime}$ end. Sequence alignment revealed 49 polymorphic sites, defining 36 distinct haplotypes (Table 2). 
Table 2. Variable sites in the control-region segment of the 36 haplotypes of swordfish mtDNA detected in the modern sample. Numbers above sites refer to nucleotide position on the L-strand of the control region of the swordfish. Identity with sequence 1 is indicated by dots and deletions of 1 residue with dashes.

\begin{tabular}{|c|c|c|c|c|c|c|c|c|c|c|c|c|c|c|c|c|c|c|c|c|c|c|c|c|c|c|c|c|c|c|c|c|c|c|c|c|c|c|c|c|c|c|c|}
\hline $\begin{array}{c}\text { Genbank } \\
\text { Accession } \\
\text { Number }\end{array}$ & 2 & 9 & 12 & 17 & 18 & 19 & 20 & 21 & 22 & 23 & 24 & 46 & 60 & $67 \quad 7$ & 7783 & $\begin{array}{ll}3 & 91\end{array}$ & 92 & 101 & $\begin{array}{ll}110 & 11\end{array}$ & 11111 & 18120 & 122 & 123 & $\begin{array}{ll}125 & 12\end{array}$ & $126 \quad 12$ & 127132 & $\begin{array}{ll}134 & 1\end{array}$ & 1351 & $138 \quad 15$ & 158159 & 160 & $\begin{array}{ll}161 & 16\end{array}$ & & $66 \quad 172$ & 173 & 178 & & & $187 \quad 190$ & $\begin{array}{ll}0 & 194\end{array}$ & & & \\
\hline AY650 & G & T & A & $\mathrm{T}$ & $\mathrm{A}$ & C & A & & - & - & - & C & A & $\mathrm{A} \quad \mathrm{C}$ & $\mathrm{A}$ & $\mathrm{T}$ & $\mathrm{T}$ & A & $\begin{array}{ll}\text { G } & \text { T }\end{array}$ & $\mathrm{T}$ & A & A & C & $\begin{array}{ll}\mathrm{T} & \mathrm{G}\end{array}$ & $\mathrm{G}$ & $\begin{array}{ll}\mathrm{T} & \mathrm{T} \\
\end{array}$ & A & c & c & $\mathrm{T}$ & $\mathrm{T}$ & $\mathrm{T}$ & A & A & $\mathrm{T}$ & C & C & $\mathrm{T}$ & $\begin{array}{ll}T & G\end{array}$ & G & $\mathrm{T}$ & A & G \\
\hline MNo52597? & & & & & & & & $\mathrm{T}$ & A & C & A & & & & & & & & - & c & & & & 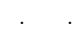 & & & & & $\mathrm{T}$ & & & & . & & & & & - & 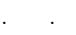 & & & & \\
\hline AY 650778 & & & & & & & & - & - & - & - & & & & & & & & . & c & & & & . & & . & & & T & & & & . & & & & & & & & & & \\
\hline AY650860 & & & & & & & & - & & 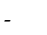 & & & & & & & & & . & C & & & & . & & . & . & & $\mathrm{T}$ & G & . & & 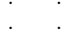 & & & & & & & & & & \\
\hline & A & & & & & & & & - & & & & & & & & & . & . . & . & . & & 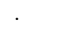 & . & . & . & & & & & . & & & & & & & & & & . & & \\
\hline & & & & & & & & & & & & & & & & & & . & . . & . & . & & . & . & . & . & & & 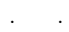 & & & & G & & & & & & & & . & & \\
\hline & & & & & & & & - & - & 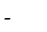 & - & & . & . . . & . G & & & & . . & . & & . & & . & & & & & & & & & & & & & & & & & & & \\
\hline & & & & & & & & $\mathrm{T}$ & A & C & A & . & & & & & . & & . & & & . & & . & & & & & . & G & & & & & & & & & & & & & \\
\hline & & & & . & & & & - & - & - & - & & & & & & & . & . & . & . & & . & C. & & & & & . & & & & & & & & & & & & & & \\
\hline & & & & & 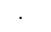 & & 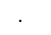 & - & - & - & - & & & & & & & 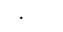 & . . & . & & & & . . & . & . . & . & & . G & G & . & & & & & & & - & . & & . & & \\
\hline $\mathrm{AY}$ & & & . & & . & & . & - & - & - & - & & & & & & & 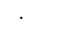 & 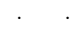 & 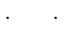 & & & & . & . & . . & . & & . C & C & ( & & & & & & & - & . & & . & & \\
\hline & & & . & & . & & . & - & - & - & - & & & . & & & & & . & 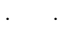 & & & & . & 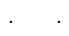 & . & 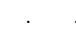 & & . & . C & . & & & & & & & 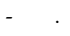 & 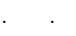 & & . & & \\
\hline & & & & & & & & - & - & - & - & & . & G . & .. & & & & . & . & & . & & & & & & & & & & & . & . & & . & & - & & & & & \\
\hline & & & & & & & & - & - & - & - & & . & . & . & & & & . &. & & . & & & & & & & & & & & G & . & & . & - & - & & & & & \\
\hline & & & & & & & & - & - & - & - & . & & . . . & . & & & & . $\quad C$ & C & & & $\mathrm{T}$ & & & & & & & & & . & . & . & & . & & - & & & & & \\
\hline M & & & & & & & & - & - & - & - & & & & & & & & . & & & & $\mathrm{T}$ & s & . & . & 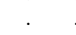 & & 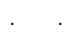 & & 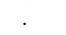 & & 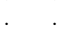 & & & & & 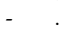 & & & . & & \\
\hline & & & . & & . & & & - & - & - & - & & & & & & & & . & & & & & . & & . & G & & 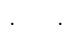 & & . & & & & & & & & & & . & & \\
\hline MN65 & & & & & . & & & - & - & 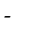 & - & & & 1 & $\Gamma$ & & & & & & & & & & & . & & & & & & & & & & & & & & & & & \\
\hline & & - & & & & & & - & - & & & & & & & & & & & & & & & & & . & & & T & & & & & & & 1 & $\mathrm{~T}$ & & A & & & & \\
\hline & & & & & & & & - & & & & & & . & . & & . & & . & . & & . & & . & & . & & 1 & & & & . & & r. & & & & & & & & & \\
\hline & & & & & & & & - & & & & & : & . & ". & & & & & . & & . & & . & A & . & & & $\mathrm{T}$ & & & & & & & G & $\mathrm{T}$ & 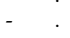 & & & & & \\
\hline & & & - & & & & & - & & & & & & & & & & & . & & & & T & & . & . & . & & & & ${ }^{\circ}$ & & & & C & & & - & & & . & & \\
\hline & & & - & & & & & - & & 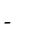 & & & $\dot{G}$ & & & & & & . & & & & T & & . & . & . & & & & . & & & & & & & - & & & & & \\
\hline & & & - & & & & & $\mathrm{T}$ & A & C & A & & & & & & & & : & & & & T & & . & . & . & & & & . & & & & & & & - & A & & $\dot{C}$ & & \\
\hline & & & - & & . & & & & & 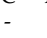 & & & & 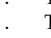 & . & & & 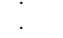 & : & &. & & 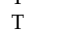 & & . & . & . & & & & . & & & & & & - & & & & . & . & A \\
\hline & & & & & & & & - & & - & & & & & & & & & & & & & $\mathrm{T}$ & & . & & & & & & & & & $\dot{G}$ & & & & & & & & & \\
\hline & & & & - & - & - & & 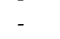 & & - & & & & & . & & : & $\dot{\mathrm{T}}$ & $\dot{C}$ & & $\dot{G}$ & 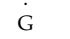 & & A & $\dot{\mathrm{C}}$ & $\begin{array}{ll}C \\
C\end{array}$ & $\dot{G}$ & & G & & $\dot{C}$ & & & . & & & & & & & & & \\
\hline & & & & & & & & & & - & & & & & & & . & 1 & & & & & & & C & C & & & & & & & & & & & & C & & & & & \\
\hline & & & & - & 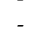 & 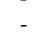 & & 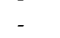 & & 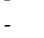 & & & & & & & & $\begin{array}{l}\mathrm{T} \\
\mathrm{T}\end{array}$ & & . & & & & & & ( & & & & & & & & & & 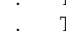 & $\mathrm{T}$ & & & & : & & \\
\hline & & & & & 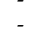 & 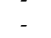 & - & 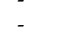 & 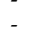 & 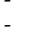 & 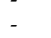 & & & & & & & $\begin{array}{l}\mathrm{T} \\
\mathrm{T}\end{array}$ & & & & & & & C & C & & & & & & C & & & & & & & & & & & \\
\hline & & & & & & & & & & - & - & $\mathrm{T}$ & & 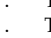 & . & & & $\mathrm{T}$ & & . & & & & & & C & & & & & & & . & & & & & & & & & & \\
\hline & & & & - & 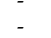 & 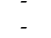 & & & & & & 1 & & & . & & $c$ & $\begin{array}{l}1 \\
\mathrm{~T}\end{array}$ & & i & & & & & & & & & & & & & & . & & & & & & & & & \\
\hline & & & & & & - & & - & & & & T & & 1 & & & & $\mathrm{~T}$ & & $\cdot$ & 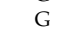 & & & & C & C & G & & & & & & & & & & & & . & & & 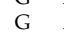 & \\
\hline & & & & - & - & - & - & - & - & - & - & $\mathrm{T}$ & & . & & & & & & & & & & & & & & & & & & & & & & & & & & & & & \\
\hline & & & & & & & & 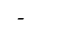 & - & & & & & 1 & & c & & & & & & & & & & & & & & & & & & & & & & & & & & & \\
\hline 227787 & & & & & & & - & - & - & - & - & & & & & & & & & & & & & & & & & & & & & & & & & & & & & & & & \\
\hline
\end{tabular}


According to Bremer et al. [12] the mtDNA haplotypes of swordfish clustered into two highly divergent clades, Clade I and Clade II. The MJ network (Figure 2) identified the two mtDNA clades.

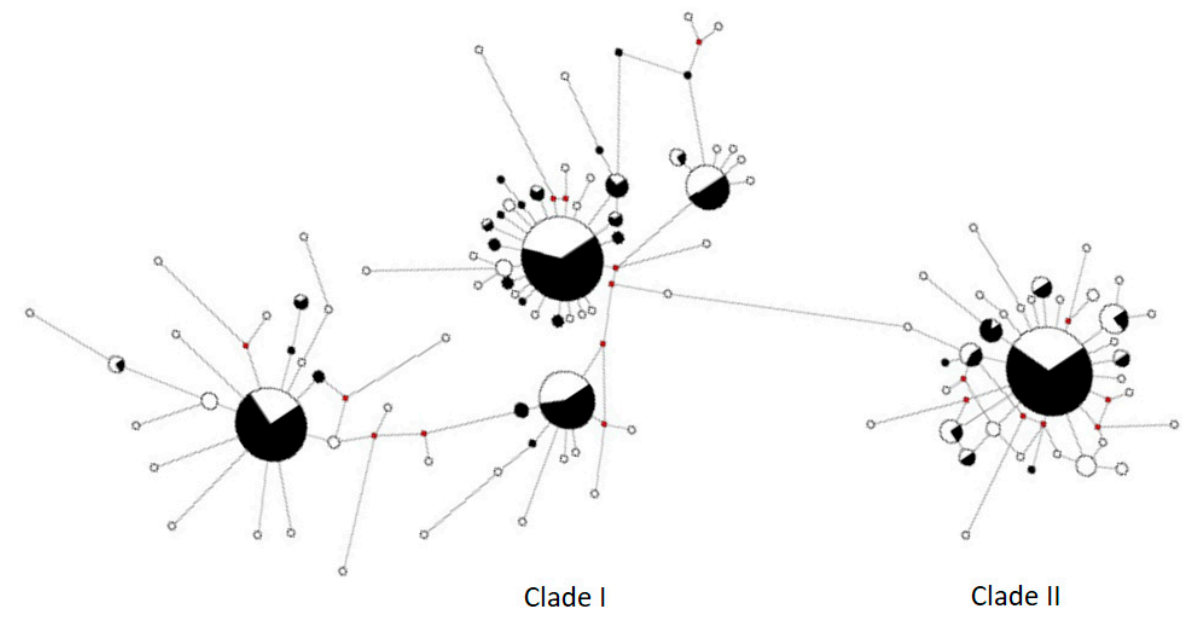

Figure 2. MJ network for the complete dataset of Mediterranean swordfish. White slices indicate haplotype observed by Viñas [17] and black slices recent sample (this work). Small red circles correspond to missing (or hypothetical) haplotypes.

Clade I included four centroids (Genbank n. AY650768, AY650763, AY650778, AY650781) represented respectively by $61,55,14$ and 25 fish, while Clade II was characterized by a single star-like formation featuring one major centroid (AY650762) with a total of 73 individuals. These five centroids haplotypes were observed with high frequencies in all Mediterranean localities investigated in this study, as already observed in previous works [10,17]. The other haplotypes, instead, were represented in very few numbers of the individuals often representing singletons. In this study seventeen, previously unidentified haplotypes were sampled. Fifteen of which belong to Clade I and two belong to Clade II and all were observed at low frequencies (Table S1). Sequences are available from the NCBI database with accession numbers MN652595-MN652611.

Comparison among historical dataset from Viñas et al. [17] and the present dataset, respectively composed by 251 and 287 swordfish, revealed the same percentage of individuals belonging to Clade I (about 66\%) and Clade II (about 33\%). However, dataset comparison indicates a reduction in the number of haplotypes from 93 in the historical to 36 in the contemporary samples (Table 3).

Table 3. Summary of molecular diversity indices for Mediterranean swordfish temporal samples for pooled clades and each clade separately. The number of individuals $(\mathrm{N})$ and haplotypes $(\mathrm{H})$, the haplotype diversity $(\mathrm{h})$, the nucleotide diversity $(\pi)$ and effective population size parameter $(\theta)$ are shown.

\begin{tabular}{cccccc}
\hline Title & $\mathbf{N}$ & $\mathbf{H}$ & $\boldsymbol{h}$ (s.d.) & $\boldsymbol{\pi}$ (s.d.) & $\boldsymbol{\theta}$ (95\% C.I.) \\
\hline Viñas et al., 2010 & & & & & \\
Clade I + II & 251 & 93 & $0.946(0.007)$ & $0.160(0.080)$ & $0.142(0.121-0.188)$ \\
$\quad$ Clade I & 156 & 60 & $0.910(0.014)$ & $0.034(0.020)$ & $0.076(0.060-0.107)$ \\
Clade II & 95 & 33 & $0.861(0.031)$ & $0.006(0.004)$ & $0.044(0.0 .29-0.062)$ \\
This study & & & & & \\
Clade I + II & 286 & 36 & $0.844(0.010)$ & $0.130(0.070)$ & $0.033(0.028-0.044)$ \\
Clade I & 190 & 26 & $0.793(0.018)$ & $0.029(0.015)$ & $0.019(0.015-0.030)$ \\
Clade II & 96 & 10 & $0.418(0.063)$ & $0.003(0.002)$ & $0.010(0.006-0.017)$ \\
\hline
\end{tabular}

Haplotype reduction was confirmed by the rarefaction curve that reported the highest haplotype richness values in the older sample (Figure 3). 


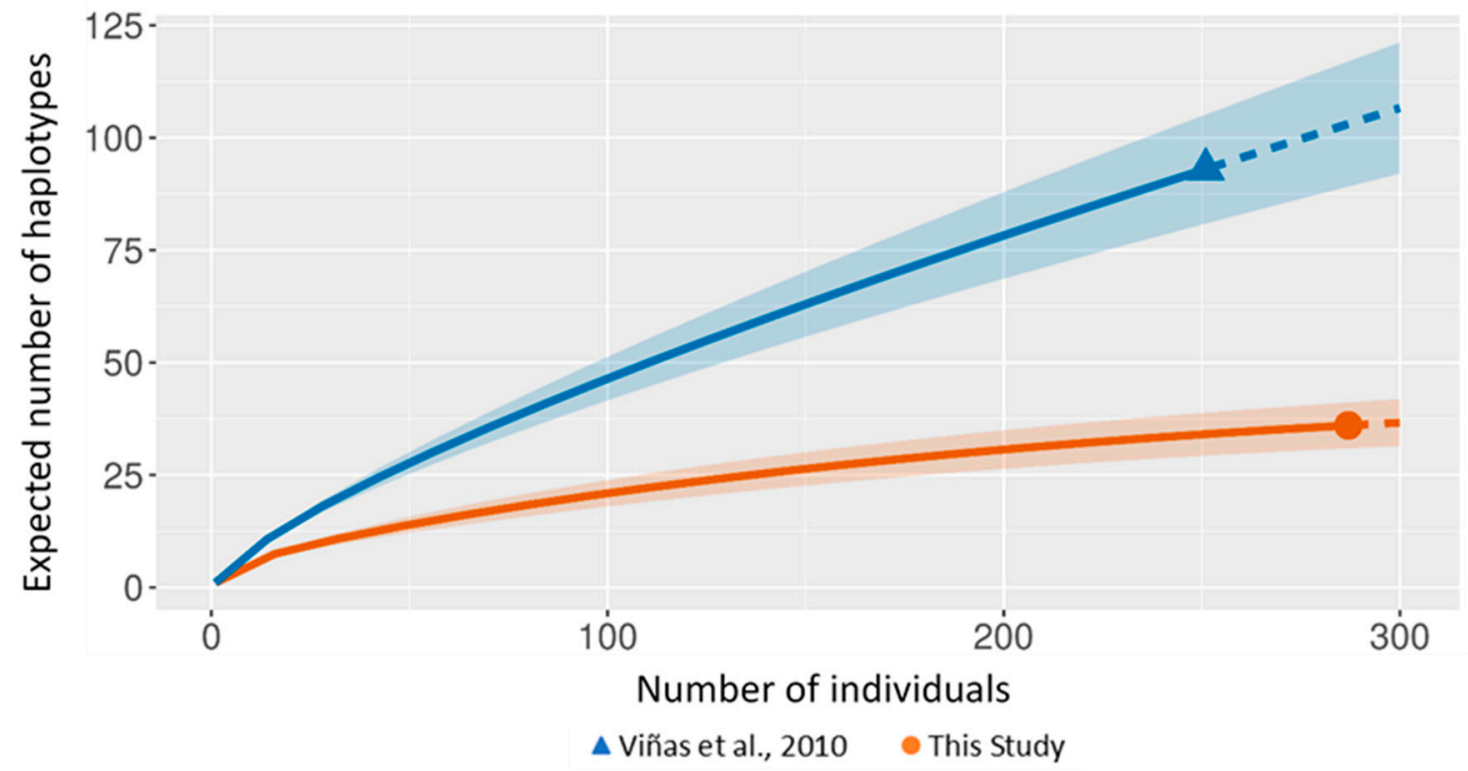

Figure 3. Size-based rarefaction (solid curves) and extrapolation (dashed curves) with $95 \%$ confidence intervals (shaded areas) comparing ancient Mediterranean swordfish (blue) and contemporary (orange) samples.

Considering the two clades separately, the observed haplotype number decreased from 60 to 26 for Clade I and from 33 to 10 for Clade II. Nineteen haplotypes were shared between datasets (11 for Clade I and 8 for Clade II). Moreover, in the modern sample, a shift towards the fixation of the main five haplotypes (i.e., centroids) was also observed (Figure 2, Table S2).

A reduction of haplotype diversity was observed between historical $(h=0.947 \pm 0.007$ s.d. $)$ and modern datasets $(h=0.844 \pm 0.01$ s.d.). Haplotype diversity decrease was more evident considering the two clades separately. For Clade I the diversity in historical samples $(h=0.91)$ was greater than the contemporary $(h=0.793)$ as well as for Clade II where diversity was $h=0.861$ in the historical sample and $h=0.418$ in the modern sample. Levels of nucleotide diversity were similar throughout the two databases. All estimates of haplotype and nucleotide diversity are given in Table 3. The AMOVA analysis identifies significant genetic differentiation between older and recent datasets. Low levels of differentiation $\left(\mathrm{F}_{\mathrm{ST}}=0.018, p<0.001\right)$ were detected between samples pooling clades and considering Clade I singularly, while historical and modern samples were moderately differentiated $\left(\mathrm{F}_{\mathrm{ST}}=0.121, p\right.$ $<0.001$ ) considering only Clade II (Table 4).

Table 4. AMOVA results of Mediterranean swordfish temporal sample comparison.

\begin{tabular}{ccccc}
\hline Source of Variation & Variance Component & Percentage of Variation & Fixation Index $\left(\phi_{\text {ST }}\right)$ & $p$-Value \\
\hline Whole dataset & & & & 0.0177 \\
Among temporal samples & 0.008 & 1.77 & & 0.0000 \\
Within samples & 0.446 & 98.23 & 0.0184 & 0.0005 \\
$\quad$ Clade I & 0.008 & 1.85 & & 0.0000 \\
Among temporal samples & 0.423 & 98.15 & 0.121 & \\
$\quad$ Within samples & 0.044 & 12.10 & & \\
$\quad$ Clade II & 0.319 & 87.90 & & \\
Among temporal samples & & & \\
Within samples & &
\end{tabular}

The older sample significantly differed from the modern one when compared through an exact test of sample differentiation. The effective population size parameters of swordfish populations were estimated for each mtDNA CR-I clade separately. The comparison of the $\theta$ values showed a reduction of the relative females' effective population size in the recent sample $(\theta=0.033,95 \%$ C.I. $0.028-0.044)$ 
compared to the historical one $(\theta=0.142,95 \%$ C.I. $0.121-0.188$ ) (Table 3). Ratios between the historical and current $\theta$ suggested a reduction of approximately three-quarters of the female population size. Estimates were congruent considering both the clades separately and pooled them together.

\section{Discussion}

In this study, for the first time, a temporal approach has been used to study recent changes in mitochondrial genetic diversity in the threatened Mediterranean swordfish. Comparison between temporal samples allows us to identify short-term changes that happened in the last few decades. Our results revealed that Mediterranean swordfish has undergone genetic depletion during the last twenty years.

The number of mitochondrial haplotypes observed in the recent sample (36 in total; 26 Clade I and 10 Clade II) was largely reduced than in previous studies [10,17]. The PCR-SSCP is a valuable tool to detect nucleotidic variation in DNA because even a single nucleotide change may alter the conformation of ssDNA. Despite this high resolving power, there is evidence that not all nucleotide modifications result in conformation changes [38]. To exclude loss of haplotypes due to the SSCP analysis we sequenced all the individuals belonging to the Clade II and all sequences confirmed the SSCP interpretation. Therefore, we consider the SSCP technique used in this paper sensitive enough to detect each single nucleotide polymorphism.

The temporal comparison based on the mtDNA genetic variability highlighted as approximately one-third of the haplotypes was lost in the last twenty years. This reduction was noticeable as a lower haplotype diversity observed on modern samples ( $h=0.84$, this study) compared to previous ones $(h=0.94)[10,17]$. When the two mitochondrial clades were analysed separately, the reduction of genetic diversity was not uniformly distributed between clades and the reduction in genetic diversity was more evident for the Clade II. Diversity comparison indicates approximately half less haplotype diversity in the contemporary Clade II samples than in the historical. Genetic differentiation between contemporary and historical swordfish was corroborated by both AMOVA and exact test results (Table 4).

The reduction in haplotype diversity with an increment in the proportion of identical haplotype and the loss of rare haplotypes observed in current Mediterranean swordfish suggest that population has undergone a demographic reduction [28]. As far as it's known, nowadays, the Mediterranean swordfish stock is considered threatened by overfishing [7]. In fact, the spawning stock biomass (SSB) estimated is less than $15 \%$ of the maximum sustainable yield ( $\mathrm{B}_{\mathrm{MSY}}$ ). From 2007-2010 the mesopelagic longline was introduced in Mediterranean swordfish fishery, substituting the traditional surface longline [7]. The two types of gears differ mainly for the depth of displacement, with the mesopelagic reaching deeper depths (50-800 m) than the traditional longline (15-60 m). Increment in fish size catch using the mesopelagic longline has revealed the presence of a bulk of large spawners, that found their refuge in the deep [39]. However, after only six years the mean swordfish size exploited shifted towards smaller sizes, in a situation very similar to that recorded in the past for surface driftnets and surface longline [40]. Thus, it is possible to assume that the mesopelagic gear catching bigger swordfish may have increased the impact on adults, affecting the spawning stock [39-41]. Specifically, mtDNA is maternally inherited therefore, the analysis of mtDNA variability reflects only the history of the Mediterranean swordfish female portion. Swordfish females reach larger sizes than males, outnumbering males in larger size classes (LJFL $>140 \mathrm{~cm}$ ) [5,39,42]. Therefore, an increase in the average size may be related to an increase in the number of mature females exploited. Furthermore, females mature at larger age and size than males, about two years later. The high percentage (50-70\%) of small fish, often still immature, reported by the annual catch estimates, may affect the number of recruited new females in the spawning stock. Comparison of $\theta_{\mathrm{s}}$ values supports the scenario of a recent population size decrease in Mediterranean swordfish stock, suggesting a reduction of approximately three-quarters of effective female population size (Table 3). Thus, the fishery may have altered the 
sex ratio, reducing the number of females in the breeding population, therefore leading to the loss in mitochondrial diversity.

Overexploitation and environmental degradation were identified as the main causes of reductions in stocks and extinction of marine species $[43,44]$. Human activities may reduce the genetic variability of the population in an extremely short period [45]. Overexploitation has been related to a decline in genetic diversity across a wide range of marine fish species [22]. The genetic diversity estimated in harvested and unharvested fish stocks over 140 species, resulted to be lower in the exploited than in the non-harvest stocks [22]. However, a limited number of studies have assessed the temporal reduction of effective population size $\left(N_{\mathrm{e}}\right)$ and the loss of genetic variation related to harvesting due to lack of historical data as well as samples. Some of these studies, using DNA extracted from archived otoliths or scales, found a loss of neutral genetic diversity in some fish species. A significant reduction in genetic diversity was described in New Zealand Hoplostethus atlanticus over only 6 years, during which time the exploitation reduced the biomass by $70 \%$ [46]. Marked genetic changes were also detected using microsatellite in the Gadus morhua Flamborough Head population across a period during which the population exhibited a decline in SSB related to high levels of exploitation [27]. Hauser [25] detected a significant decline in genetic diversity in a New Zealand snapper population over the 50 years since the onset of exploitation. Moreover, in Adriatic European anchovy (Engraulis encrasicolus) a significant reduction of mean genetic parameters have been detected and related to the stock collapse in 1987 [47]. The number of fish in a population (census population size, $N$ ) is often much larger than the fish that are reproducing and helping to maintain genetic diversity (the genetically effective population size, $N_{\mathrm{e}}$ ). Hauser [25] using the $N_{e} / N$ estimate in snapper suggested that fish stocks of several million individuals may be in danger of losing genetic variability in the long term. Considering that, globally $31 \%$ of fish populations are fished unsustainably, with an additional $60 \%$ fully fished [48], fishing may have already caused a considerable loss of overall biodiversity.

This study reports the first direct measure of reduction in genetic diversity for Mediterranean swordfish during a short period, as measured both in the direct loss of mitochondrial haplotypes and reductions in haplotype diversity. Genetic changes observed in this study suggest that reduction in the SSB of Mediterranean swordfish caused significant changes in genetic composition. The significant loss of mitochondrial diversity in Mediterranean swordfish over a short period is alarming because the rapid loss of genetic diversity has been shown to have harmful effects. Reduction in genetic diversity, coupled with low population size [20] and reproductive isolation [2], can disfavour Mediterranean swordfish recovery. This may result in genetic drift and inbreeding depression and reduction in fitness limiting long-term adaptability [23,24], particularly if abundance remains low and diversity continues to decay [22]. This result underlines the urgent necessity to re-evaluate management strategies of the swordfish in the Mediterranean Sea.

Supplementary Materials: The following are available online at http://www.mdpi.com/1424-2818/12/5/170/s1, Table S1. Haplotype frequencies observed have been reported for each sample locality, Table S2. GenBank accession numbers of the mtDNA CR haplotypes, clade assignment and frequencies observed in each temporal sample, Table S3. Predicted fragment sizes (bp) of a 290 bps long portion of the mitochondrial control region virtually double-digested with VspI and PacI, Table S4. Variable sites in the control-region segment of all 110 haplotypes of swordfish mtDNA detected in Viñas et al., 2010 and this work (in bold). Numbers above sites refer to nucleotide position on the L-strand of the control region of the swordfish. Identity with sequence 1 is indicated by dots and deletions of 1 residue with dashes.

Author Contributions: Conceptualization, T.R.; Methodology, T.R.; Formal analysis, T.R.; Investigation, T.R.; Resources, G.G. and V.C.B.; Data curation, E.C., T.R.; Writing-Original draft preparation, T.R.; Writing-Review and editing, A.S., T.F. and T.R.; Visualization, T.R.; Supervision, V.C.B.; Project administration, G.G.; Funding acquisition, O.C. All authors have read and agreed to the published version of the manuscript.

Funding: This work was funded by the Ministry of Agriculture, Food and Forestry Policies (MIPAAF), note 6775, Art.36 Paragraph 1 Reg (UE9 n 508/2014) to O.C.

Acknowledgments: We truly thank the fishermen, Pesca Pronta Import-Export s.r.l. for their extremely precious collaboration during sampling activities. The authors wish to thank all the staff at OCEANIS s.r.l. (Ercolano, Naples) for the support in sampling activities. 
Conflicts of Interest: The authors declare no conflict of interest.

\section{References}

1. Palko, B.J.; Beardsley, G.L.; Richards, W.J. Synopsis of the biology of the swordfish, Xiphias gladius (L.). U.S. Dep. Commer. NOAA Tech. Rep. NMFS Circ. 1981, 441, 21.

2. Neilson, J.; Arocha, F.; Cass-Calay, S.; Mejuto, J.; Ortiz, M.; Scott, G.; Smith, C.; Travassos, P.; Tserpes, G.; Andrushchenko, I. The recovery of Atlantic swordfish: The comparative roles of the regional fisheries management organization and species biology. Rev. Fish. Sci. 2013, 21, 59-97. [CrossRef]

3. Abascal, F.J.; Mejuto, J.; Quintans, M.; García-Cortés, B.; Ramos-Cartelle, A. Tracking of the broadbill swordfish, Xiphias gladius, in the central and eastern North Atlantic. Fish. Res. 2015, 162, 20-28. [CrossRef]

4. Arocha, F. Swordfish Reproduction in the Atlantic Ocean: An Overview. GCR 2007, 19. [CrossRef]

5. Marisaldi, L.; Basili, D.; Candelma, M.; Sesani, V.; Pignalosa, P.; Gioacchini, G.; Carnevali, O. Maturity assignment based on histology-validated macroscopic criteria: Tackling the stock decline of the Mediterranean swordfish (Xiphias gladius). Aquat. Conserv. Mar. Freshw. Ecosyst. 2020, 30, 303-314. [CrossRef]

6. Macías, D.; Hattour, A.; De la Serna, J.M.; Gómez-Vives, M.J.; Godoy, D. Reproductive characteristics of swordfish (Xiphias gladius) caught in the southwestern Mediterranean during 2003. Collect. Vol. Sci. Pap. ICCAT 2005, 58, 454-469.

7. Anon. Report for Biennial Period, 2018-19 PART I (2018)_Volume 2; International Commission for the Conservation of Atlantic Tunas: Madrid, Spain, 2019; pp. 182-192.

8. Bremer, J.A.; Mejuto, J.; Gómez-Márquez, J.; Pla-Zanuy, C.; Viñas, J.; Marques, C.; Hazin, F.; Griffiths, M.; Ely, B.; García-Cortés, B. Genetic population structure of Atlantic swordfish: Current status and future directions. Collect. Vol. Sci. Pap. ICCAT 2007, 61, 107-118.

9. Viñas, J.; Bremer, J.A.; Pla, C. Inter-oceanic genetic differentiation among albacore (Thunnus alalunga) populations. Mar. Biol. 2004, 145, 225-232. [CrossRef]

10. Bremer, J.R.A.; Viñas, J.; Mejuto, J.; Ely, B.; Pla, C. Comparative phylogeography of Atlantic bluefin tuna and swordfish: The combined effects of vicariance, secondary contact, introgression, and population expansion on the regional phylogenies of two highly migratory pelagic fishes. Mol. Phylogenetics Evol. 2005, 36, 169-187. [CrossRef]

11. Šegvić-Bubić, T.; Marrone, F.; Grubišić, L.; Izquierdo-Gomez, D.; Katavić, I.; Arculeo, M.; Brutto, S.L. Two seas, two lineages: How genetic diversity is structured in Atlantic and Mediterranean greater amberjack Seriola dumerili Risso, 1810 (Perciformes, Carangidae). Fish. Res. 2016, 179, 271-279. [CrossRef]

12. Bremer, J.R.A.; Mejuto, J.; Greig, T.W.; Ely, B. Global population structure of the swordfish (Xiphias gladius L.) as revealed by analysis of the mitochondrial DNA control region. J. Exp. Mar. Biol. Ecol. 1996, 197, 295-310. [CrossRef]

13. Rosel, P.E.; Block, B.A. Mitochondrial control region variability and global population structure in the swordfish, Xiphias gladius. Mar. Biol. 1996, 125, 11-22. [CrossRef]

14. Chow, S.; Okamoto, H.; Uozumi, Y.; Takeuchi, Y.; Takeyama, H. Genetic stock structure of the swordfish (Xiphias gladius) inferred by PCR-RFLP analysis of the mitochondrial DNA control region. Mar. Biol. 1997, 127, 359-367. [CrossRef]

15. Muths, D.; Grewe, P.; Jean, C.; Bourjea, J. Genetic population structure of the Swordfish (Xiphias gladius) in the southwest Indian Ocean: Sex-biased differentiation, congruency between markers and its incidence in a way of stock assessment. Fish. Res. 2009, 97, 263-269. [CrossRef]

16. Reeb, C.A.; Arcangeli, L.; Block, B.A. Structure and migration corridors in Pacific populations of the Swordfish Xiphius gladius, as inferred through analyses of mitochondrial DNA. Mar. Biol. 2000, 136, 1123-1131. [CrossRef]

17. Viñas, J.; Pérez-Serra, A.; Vidal, O.; Alvarado Bremer, J.R.; Pla, C. Genetic differentiation between eastern and western Mediterranean swordfish revealed by phylogeographic analysis of the mitochondrial DNA control region. ICES J. Mar. Sci. 2010, 67, 1222-1229. [CrossRef]

18. Bremer, J.R.A.; Baker, A.J.; Mejuto, J. Mitochondrial DNA control region sequences indicate extensive mixing of swordfish (Xiphias gladius) populations in the Atlantic Ocean. Can. J. Fish. Aquat. Sci. 1995, 52, 1720-1732. [CrossRef] 
19. Pujolar, J.M.; Roldan, M.I.; Pla, C. A genetic assessment of the population structure of swordfish (Xiphias gladius) in the Mediterranean Sea. J. Exp. Mar. Biol. Ecol. 2002, 276, 19-29. [CrossRef]

20. Kotoulas, G.; Mejuto, J.; Antoniou, A.; Kasapidis, P.; Tserpes, G.; Piccinetti, C.; Peristeraki, P.; Garcia-Cortes, B.; Oikonomaki, K.; De la Serna, J.M. Global genetic structure of swordfish (Xiphias gladius) as revealed by microsatellite DNA markers. Collect. Vol. Sci. Pap. ICCAT 2007, 61, 79-88.

21. Xiphias gladius (errata version published in 2016). The IUCN Red List of Threatened Species 2011: e.T23148A88828055. Available online: https://dx.doi.org/10.2305/IUCN.UK.2011-2.RLTS.T23148A9422329.en. (accessed on 17 December 2017).

22. Pinsky, M.L.; Palumbi, S.R. Meta-analysis reveals lower genetic diversity in overfished populations. Mol. Ecol. 2014, 23, 29-39. [CrossRef]

23. Frankham, R. Genetics and extinction. Biol. Conserv. 2005, 126, 131-140. [CrossRef]

24. Spielman, D.; Brook, B.W.; Frankham, R. Most species are not driven to extinction before genetic factors impact them. Proc. Natl. Acad. Sci. USA 2004, 101, 15261-15264. [CrossRef]

25. Hauser, L.; Adcock, G.J.; Smith, P.J.; Ramírez, J.H.B.; Carvalho, G.R. Loss of microsatellite diversity and low effective population size in an overexploited population of New Zealand snapper (Pagrus auratus). Proc. Natl. Acad. Sci. USA 2002, 99, 11742-11747. [CrossRef]

26. Turner, T.F.; Wares, J.P.; Gold, J.R. Genetic effective size is three orders of magnitude smaller than adult census size in an abundant, estuarine-dependent marine fish (Sciaenops ocellatus). Genetics 2002, 162, 1329-1339.

27. Hutchinson, W.F.; Oosterhout, C.; Rogers, S.I.; Carvalho, G.R. Temporal analysis of archived samples indicates marked genetic changes in declining North Sea cod (Gadus morhua). Proc. R. Soc. Lond. Ser. B Biol. Sci. 2003, 270, 2125-2132. [CrossRef]

28. Allendorf, F.W.; England, P.R.; Luikart, G.; Ritchie, P.A.; Ryman, N. Genetic effects of harvest on wild animal populations. Trends Ecol. Evol. 2008, 23, 327-337. [CrossRef] [PubMed]

29. Thompson, J.D.; Gibson, T.J.; Higgins, D.G. Multiple sequence alignment using ClustalW and ClustalX. Curr. Protoc. Bioinform. 2003, 1, 2-3. [CrossRef] [PubMed]

30. Hall, T.A. BioEdit: A user-friendly biological sequence alignment editor and analysis program for Windows 95/98/NT. Nucleic Acids Symp. Ser. 1999, 41, 95-98.

31. Excoffier, L.; Lischer, H.E. Arlequin suite ver 3.5: A new series of programs to perform population genetics analyses under Linux and Windows. Mol. Ecol. Resour. 2010, 10, 565-567. [CrossRef] [PubMed]

32. Heck, K.L., Jr.; van Belle, G.; Simberloff, D. Explicit calculation of the rarefaction diversity measurement and the determination of sufficient sample size. Ecology 1975, 56, 1459-1461. [CrossRef]

33. Hsieh, T.C.; Ma, K.H.; Chao, A. iNEXT: An R package for rarefaction and extrapolation of species diversity (H ill numbers). Methods Ecol. Evol. 2016, 7, 1451-1456. [CrossRef]

34. Chao, A.; Gotelli, N.J.; Hsieh, T.C.; Sander, E.L.; Ma, K.H.; Colwell, R.K.; Ellison, A.M. Rarefaction and extrapolation with Hill numbers: A framework for sampling and estimation in species diversity studies. Ecol. Monogr. 2014, 84, 45-67. [CrossRef]

35. Bandelt, H.-J.; Forster, P.; Röhl, A. Median-joining networks for inferring intraspecific phylogenies. Mol. Biol. Evol. 1999, 16, 37-48. [CrossRef] [PubMed]

36. Excoffier, L.; Smouse, P.E.; Quattro, J.M. Analysis of molecular variance inferred from metric distances among DNA haplotypes: Application to human mitochondrial DNA restriction data. Genetics 1992, 131, 479-491. [PubMed]

37. Kuhner, M.K. LAMARC 2.0: Maximum likelihood and Bayesian estimation of population parameters. Bioinformatics 2006, 22, 768-770. [CrossRef]

38. Hayashi, K.; Yandell, D.W. How sensitive is PCR-SSCP? Hum. Mutat. 1993, 2, 338-346. [CrossRef]

39. Garibaldi, F. Effects of the introduction of the mesopelagic longline on catches and size structure of swordfish in the Ligurian sea (western Mediterranean). Collect. Vol. Sci. Pap. ICCAT 2015, 71, 2006-2014.

40. Garibaldi, F.; Lanteri, L. Notes about a tagged/recaptured swordfish in the Ligurian Sea (western Mediterranean). Collect. Vol. Sci. Pap. ICCAT 2017, 74, 1354-1361.

41. Bertolino, F.; Camolese, C.; Dell'Aquila, M.; Mariani, A.; Valastro, M. Swordfish (Xiphias gladius L.) fisheries using mesopelagic longline in the Mediterranean Sea by Italian fishing fleet. Collect. Vol. Sci. Pap. ICCAT 2015, 71, 2073-2078.

42. Abid, N.; Laglaoui, A.; Arakrak, A.; Bakkali, M. The reproductive biology of swordfish (Xiphias gladius) in the Strait of Gibraltar. J. Mar. Biol. Assoc. U. K. 2019, 99, 649-659. [CrossRef] 
43. Dulvy, N.K.; Sadovy, Y.; Reynolds, J.D. Extinction vulnerability in marine populations. Fish Fish. 2003, 4, 25-64. [CrossRef]

44. Dulvy, N.K.; Jennings, S.; Rogers, S.I.; Maxwell, D.L. Threat and decline in fishes: An indicator of marine biodiversity. Can. J. Fish. Aquat. Sci. 2006, 63, 1267-1275. [CrossRef]

45. Kenchington, E.L. 14 The Effects of Fishing on Species and Genetic Diversity. Responsible Fish. Mar. Ecosyst. 2003, 235.

46. Smith, P.J.; Francis, R.; McVeagh, M. Loss of genetic diversity due to fishing pressure. Fish. Res. 1991, 10, 309-316. [CrossRef]

47. Ruggeri, P.; Splendiani, A.; Di Muri, C.; Fioravanti, T.; Santojanni, A.; Leonori, I.; De Felice, A.; Biagiotti, I.; Carpi, P.; Arneri, E. Coupling demographic and genetic variability from archived collections of European anchovy (Engraulis encrasicolus). PLoS ONE 2016, 11, e0151507. [CrossRef] [PubMed]

48. FAO. The state of world fisheries and aquaculture 2016. Contributing to Food Security and Nutrition for all; FAO: Rome, Italy, 2016.

(C) 2020 by the authors. Licensee MDPI, Basel, Switzerland. This article is an open access article distributed under the terms and conditions of the Creative Commons Attribution (CC BY) license (http://creativecommons.org/licenses/by/4.0/). 